\title{
SERUM ACTIVITIES OF LIVER ENZYMES IN WORKERS EXPOSED TO SUB-TLV LEVELS OF DIMETHYLFORMAMIDE
}

\author{
JINJIANG HE ${ }^{1}$, JIE LIU ${ }^{2}$, YULIN KONG ${ }^{2}$, WEIWEI YANG ${ }^{3}$, and ZENGLI ZHANG ${ }^{1}$
}

${ }^{1}$ Soochow University, Suzhou, China

Department of Occupational Medicine

${ }^{2}$ No. 5 Suzhou People's Hospital, Suzhou, China

Department of Occupational Diseases

${ }^{3}$ Centers for Disease Control and Prevention of Industrial Park, Suzhou, China

Physical Examination Center

\begin{abstract}
Objectives: The aim of this study has been to investigate serum activities of liver enzymes in workers exposed to sub-TLV levels of dimethylformamide (DMF). Material and Methods: Seventy-two workers and 72 healthy controls participated in the study. All subjects underwent complete physical examinations and abdominal ultrasound examination. Serum aspartate aminotransferase (AST), alanine aminotransferase (ALT), and c-glutamyl transpeptidase (c-GT) were determined by an auto-chemistry analyzer. The data of airborne concentrations of DMF was obtained from the local Center of Disease Control and Prevention. The level of urine N-acetyl-S-(N-methylcarbamoyl)cysteine (AMCC) was measured by means of high-performance liquid chromatography. Results: Time weighted average (TWA) concentration of the DMF in workplace was 18.6 (range: 9.8-36.2) mg/m³ . The concentration of the AMCC in workers' urine was 28.32 (range: 1.8-58.6) mg/l and 9 workers' AMCC exceeded the biological exposure index $(40 \mathrm{mg} / \mathrm{l})$. Thirty-one workers reported gastrointestinal symptoms (abdominal pain, nausea, anorexia) and 10 workers reported headache, dizziness and/or palpitation in the exposed group. Serum analysis revealed that both the mean of serum activities of liver enzymes (ALT, AST and c-GT) and the percentage of workers with abnormal liver function were significantly higher in the exposed group as compared to the controls. Conclusions: Dimethylformamide can cause liver damage even if air concentration is in the sub-threshold limit value (sub-TLV) level. The protection of skin contact against the exposure to the DMF might be a critical issue as far as the occupational health is concerned.
\end{abstract}

Key words:

Dimethylformamide, Workers, Liver enzymes, TWA, Sub-TLV, Urine

\section{INTRODUCTION}

The dimethylformamide (DMF) is miscible with water and most organic solvents and is widely used in industry, especially in factories handling polyurethane materials and acrylic fibers [1]. It is a well-recognized fact that overexposure to the DMF could result in hepatotoxicity. China is the largest producer and consumer of the DMF in the world. The environmental airborne DMF is a good index to evaluate the general situation in the workplaces. Regular air monitoring of the DMF is required by the

The work was supported by Jiangsu Key Laboratory of Preventive and Translational Medicine for Geriatric Diseases.

Received: October 23, 2013. Accepted: September 3, 2014.

Corresponding author: Z. Zhang, Soochow University, Department of Occupational Medicine, Renai Road 199, Industrial Park, Suzhou, China (e-mail: zhangzengli@suda.edu.cn) 
government. The current threshold limit value (TLV) for the DMF in the workplace is $20 \mathrm{mg} / \mathrm{m}^{3}(8 \mathrm{~h}$-TWA (timeweighted average)) in China. Multi-intervention measures have contributed to the substantial decrease in the concentration of the DMF in the workplaces [2]. However, frequently reported cases have indicated that hepatotoxicity caused by the DMF exposure is still a concern in China [3,4]. Biological monitoring is a precise approach for the occupational exposure assessment and prevention of adverse effects. The N-acetyl-S-(N-methylcarbamoyl) cysteine (AMCC), a metabolite of the DMF, has long half-life of 23-34 $\mathrm{h}$ and accumulates in the human body and has been used to evaluate the DMF exposure [5]. In this study, a cross-sectional study has been undertaken to study serum activities of liver enzymes in workers exposed to sub-TLV levels of the DMF.

\section{MATERIAL AND METHODS}

The study subjects worked in a factory that manufactures synthetic leather by mixing the DMF, resin and other chemicals. Seventy-two subjects who were occupationally exposed to the DMF with minimum of 1 year were recruited for this study. They were sex and age matched with 72 control subjects who had no exposure to the DMF. Pregnant workers, and workers with continuous medication during the last 2 months, hepatic-related diseases, hepatitis B virus (HBV) and alcohol consumption exceeding $25 \mathrm{~g} /$ day were excluded from this study. Characteristics of workers are shown in the Table 1. Each subject gave a written informed consent and the local ethics committee approved the study. Each subject was interviewed by a physician. All subjects underwent complete physical examinations and abdominal ultrasound examination. Serum aspartate aminotransferase (AST), alanine aminotransferase (ALT), and c-glutamyl transpeptidase (c-GT) were determined by an auto-chemistry analyzer (Olympus AU640, PA, USA). The surface antigen of the hepatitis B virus (HBsAg) was measured by ELISA to confirm the lack of HBV carriers.
Table 1. Characteristics of study groups

\begin{tabular}{lcc}
\hline \multirow{1}{*}{\multicolumn{1}{c}{ Variable }} & \multicolumn{2}{c}{ Group } \\
\cline { 2 - 3 } & $\begin{array}{r}\text { exposed } \\
(\mathrm{N}=72)\end{array}$ & $\begin{array}{c}\text { control } \\
(\mathrm{N}=72)\end{array}$ \\
\hline Age (years) $(\mathrm{M} \pm \mathrm{SD})$ & $32.00 \pm 5.2$ & $32.00 \pm 5.8$ \\
Male (n) & 53 & 53 \\
Body mass index $(\mathrm{M} \pm \mathrm{SD})$ & $21.60 \pm 1.50$ & $22.30 \pm 1.40$ \\
Smoking $(\mathrm{n})$ & 8 & 10 \\
Exposure $($ years $)(\mathrm{M} \pm \mathrm{SD})$ & $5.00 \pm 2.80$ & 0 \\
Urinary AMCC $(\mathrm{mg} / \mathrm{l})(\mathrm{M} \pm \mathrm{SD})$ & $28.32 \pm 8.07$ & $2.21 \pm 0.47$ \\
\hline
\end{tabular}

M - mean; SD - standard deviation; AMCC - N-acetyl-S-(N-methylcarbamoyl)cysteine.

The data of airborne concentrations of DMF was obtained from the local Center of Disease Control and Prevention (CDC) which monitors the workplace 4 times per year. The level of urine N-acetyl-S-(N-methylcarbamoyl)cysteine (AMCC) was measured by high-performance liquid chromatography (HPLC) with a photodiode array (PDA) detector (Waters 2695, MA, USA). In brief, urine samples were filtered by solid phase extraction and the separation was carried out on a C18 reserved-phase column. The coefficients of variation were below $3 \%$. The limit of detection was $0.4 \mathrm{mg} / \mathrm{l}$. The calibration curve was linear up to $50 \mathrm{mg} / \mathrm{l}$.

Data was analyzed using the Student's t-test and $\mathrm{Chi}^{2}$ by the SPSS statistical package (v. 11.0). Results were expressed in terms of means \pm standard error of the mean $(\mathrm{M} \pm \mathrm{SEM})$.

\section{RESULTS}

The data from the local CDC indicated the TWA concentration of the DMF in workplaces to stand at $18.6 \mathrm{mg} / \mathrm{m}^{3}$ (range: $9.8-36.2 \mathrm{mg} / \mathrm{m}^{3}$ ), which was below TLV. However, the wide fluctuation of concentrations indicated the possibility of occasional overexposure. The concentration of the AMCC in workers' urine was $28.32 \mathrm{mg} / \mathrm{l}$ (range: $1.8-58.6 \mathrm{mg} / \mathrm{l}$ ) and 9 workers' AMCC exceeded the biological exposure index (Table 1). 
Table 2. Liver function in study groups*

Liver function

$(\mathrm{M} \pm \mathrm{SD})$

$(\mathrm{U} / \mathrm{l})$

\begin{tabular}{lcccc}
\cline { 2 - 4 } \multicolumn{1}{c}{ Group } & AST & ALT & c-GT & abnormal \\
& $($ normal range: & $\begin{array}{c}\text { ALrmal range: } \\
\text { (normal range: }\end{array}$ & $(\%-32 \mathrm{U} / \mathrm{l})$ \\
\hline Exposed $(\mathrm{N}=72)$ & $33.6 \pm 11.7$ & $35.6 \pm 14.8$ & $27.5 \pm 10.3$ & 29.20 \\
Control $(\mathrm{N}=72)$ & $21.3 \pm 6.3$ & $23.1 \pm 7.6$ & $20.1 \pm 5.9$ & 4.20 \\
$\mathrm{p}$ & $<0.01$ & $<0.01$ & $<0.01$ & $<0.01$ \\
\hline
\end{tabular}

* Both the mean of serum activities of liver enzymes and the percentage of workers with abnormal liver function were significantly higher in the exposed group as compared to the controls.

AST - aspartate aminotransferase; ALT - alanine aminotransferase; c-GT - c-glutamyl transpeptidase.

Other abbreviations as in the Table 1.

In the exposed group, 31 workers (43.1\%) reported gastrointestinal symptoms (abdominal pain, nausea, anorexia) and 10 workers $(13.8 \%)$ reported headache, dizziness and/or palpitation. Three workers with steatohepatitis, 1 worker with hepatic schistosomiasis and 5 workers with hepatic cyst were found by ultrasound in the exposed group. Four workers with steatohepatitis and 3 workers with hepatic cyst were found in the control group.

The serum analysis revealed that both the mean of serum activities of liver enzymes (ALT, AST and c-GT) and the percentage of workers with abnormal liver function (none of ALT, AST and c-GT exceed the normal range) were significantly higher in the exposed group as compared to the controls (Table 2).

\section{DISCUSSION}

High prevalence of liver function abnormalities was found in workers exposed to sub-TLV level of the DMF. Since those knowing non-occupational factors were excluded from this study, it is supposed that higher liver enzyme levels in the workers in this study are related to the DMF exposure. The DMF is a well-known hepatotoxic chemical. However, whether a lower level of the DMF exposure induces liver damage is still a controversy. Our findings are in agreement with the observations of Qian et al., who have found that the DMF can cause liver function alternations even if air concentration of the DMF is kept below the permissible concentration-time weighed average (PC-TWA) [6]. Luo et al. also reported $27 \%$ of abnormal liver function tests among workers with the DFM exposure kept below 10 ppm [7]. Therefore, liver functions of workers exposed to sub-TLV levels of the DMF deserve further study, especially in Chinese population. Nine workers' urine AMCC concentrations exceed the limits $(40 \mathrm{mg} / \mathrm{l})$ notwithstanding the exposure to the DMF air concentrations as kept below TLVs, which indicates skin absorption that might occur in the workers. The DMF dermal exposure plays a great role in the DMF absorption or accidental skin contamination because workers may be exposed to the DMF repeatedly. It has been reported that the DMF exposure through skin contact is related to a great degree to the DMFinduced total body burden [8-10]. In addition, genetic polymorphism of the DMF metabolizing enzymes might cause elevated urine AMCC.

\section{CONCLUSIONS}

In conclusion, we have found significantly abnormal serum activities of liver enzymes in workers with sub-TLV level of the DMF exposure. The protection of skin against the 
exposure to the DMF might be a critical issue as far as the occupational health is concerned.

\section{REFERENCES}

1. American Conference of Governmental Industrial Hygienists. Documentation for DMF. Cincinnati (OH): ACGIH; 2001.

2. Qian YL, Xu CM, Lu YY, Wang YH, Wu H, Zhang X. [The interventions effect-assessment of the workers exposed to $\mathrm{N}, \mathrm{N}$-dimethylformamide by percutaneous in a synthetic leather factory]. Zhonghua Lao Dong Wei Sheng Zhi Ye Bing Za Zhi. 2011 Jun;29(6):405-8. Chinese.

3. Jin LP, Ding YL, Han CH. [Lessons from a case exposed to dimethylformamide of severe chronic toxic liver disease]. Zhonghua Lao Dong Wei Sheng Zhi Ye Bing Za Zhi. 2012 Jan;30(1):70-1. Chinese.

4. Zhang XT, Kuang XY, Feng YM. [Clinical report of occupational acute dimethylformamide poisoning]. Zhonghua Lao Dong Wei Sheng Zhi Ye Bing Za Zhi. 2011 Jun;29(6):445-6. Chinese.

5. Käfferlein HU, Ferstl C, Burkhart-Reichl A, Hennebrüder K, Drexler H, Brüning T, et al. The use of biomarkers of exposure of N,N-dimethylformamide in health risk assessment and occupational hygiene in the polyacrylic fibre industry. Occup Environ Med. 2005;62(5):330-6, http://dx.doi.org/ 10.1136/oem.2004.017129.
6. Qian YL, Xu CM, Zhu LJ, Xian JX, Chai JR, Ruan Z, et al. [Abnormal liver function associated with occupational exposure to $\mathrm{N}, \mathrm{N}$-dimethylformamide in synthetic leathers works]. Zhonghua Lao Dong Wei Sheng Zhi Ye Bing Za Zhi. 2007;25(2):80-3. Chinese.

7. Luo JC, Kuo HW, Cheng TJ, Chang MJ. Abnormal liver function associated with occupational exposure to dimethylformamide and hepatitis B virus. J Occup Environ Med. 2001;43(5):474-82, http://dx.doi.org/10.1097/000437 64-200105000-00008.

8. Mráz J, Nohová H. Percutaneous absorption of N,Ndimethylformamide in humans. Int Arch Occup Environ Health. 1992;64(2):79-83, http://dx.doi.org/10.1007/ BF00381473.

9. Nomiyama T, Nakashima H, Chen LL, Tanaka S, Miyauchi H, Yamauchi T, et al. N,N-dimethylformamide: Significance of dermal absorption and adjustment method for urinary $\mathrm{N}$-methylformamide concentration as a biological exposure item. Int Arch Occup Environ Health. 2001;74 (3):224-8, http://dx.doi.org/10.1007/s004200000207.

10. Chang HY, Tsai CY, Lin YQ, Shih TS, Lin WC. Total body burden arising from a week's repeated dermal exposure to N,N-dimethylformamide. Occup Environ Med. 2005 Mar;62(3):151-6, http://dx.doi.org/10.1136/ oem.2004.016089.

This work is available in Open Access model and licensed under a Creative Commons Attribution-NonCommercial 3.0 Poland License - http://creativecommons.org/ licenses/by-nc/3.0/pl/deed.en. 